\title{
PENGARUH APLIKASI ENDOSULFAN TERHADAP KERAGAAN PRODUKSI UDANG WINDU (penaeus monodon) DAN BANDENG (Chanos chanos) DI TAMBAK
}

\author{
Muhammad Tjaronge") dan P.R. Pong-Masak
}

\begin{abstract}
ABSTRAK
Penelitian bertujuan mengetahui pengaruh aplikasi tingkat dosis endosulfan terhadap produksi dan residu dalam tubuh udang windu dan bandeng di tambak. Penelitian dilakukan selama tiga bulan dari bulan Mei sampai Juli 1996 di Instalasi Tambak Percobaan Maranak, Balai Penelitian Perikanan Pantai, Maros. Percobaan diawali dengan persiapan tambak, kemudian tiodan diaplikasikan dengan dosis 0,5 L/ha, $1 \mathrm{~L} / \mathrm{ha}$, dan $2 \mathrm{~L} /$ ha masing-masing dengan dua kali ulangan, kemudian dilakukan pencucian kembali terhadap tiodan yang telah diaplikasikan. Pemupukan dengan Urea: TSP $(2: 1)$ dilakukan untuk menumbuhkan pakan alami. Padat penebaran benur windu (PL20) dan gelondongan bandeng masing-masing 2.000 dan 150 ekor/ $500 \mathrm{~m}^{2}$, diberi pakan $10 \%$ dari bobot biomassa per hari. Penimbangan bobot udang, bandeng, dan pemantauan peubah kualitas air setiap 15 hari, serta pengamatan residu endosulfan pada daging bandeng dilakukan di laboratorium setiap 30 hari. Hasil penelitian menunjukkan produksi udang windu tertinggi pada aplikasi tiodan $2 \mathrm{~L} / \mathrm{ha}(29,1 \pm 5 \mathrm{~kg})$, sedangkan produksi bandeng tertinggi pada aplikasi tiodan $1 \mathrm{~L} / \mathrm{ha}(26,6 \pm 6 \mathrm{~kg})$. Hasil analisis residu endosulfan dalam daging bandeng memperlihatkan nilai tidak terdeteksi sampai $3.879,36$ ppb dan udang windu dengan nilai tidak terdeteksi sampai $1,645,77 \mathrm{ppb}$. Analisis residu endosulfan cenderung menurun dengan semakin lamanya pemeliharaan, sehingga memproduksi bandeng dan udang pada aplikasi tiodan $1 \mathrm{~L} /$ ha merupakan alternatif terbaik karena aman dari residu endosulfan.
\end{abstract}

\begin{abstract}
Effect of endosulphane applied on shrimp (Penaeus monodon) and milkfish (Chanos chanos) production. By: Muhammad Tjaronge and P.R. Pong-Masak

This experiment was aimed to determine the effect of endosulphane applied at different dosages on shrimp and milkfish production and level of residu in the body of animal. The study was carried out in the Installation of Experimental Pond, Maranak. Balitkanta Maros, started from May to July 1996. Pond preparation was done before applying thiodan. Various dosages of thiodan applied as a treatment were $0.5 \mathrm{~L} / \mathrm{h}$ a, $1 \mathrm{~L} / \mathrm{h}$ a, $2 \mathrm{~L} / \mathrm{h}$ a with two replicates. Urea and TSP ratio of 2:1 were used to bloom phytoplankton. The fish test was 2000 stunted shrimp combined with 150 milkfish/500 $m^{2}$ for each treatment. Feed was given at $10 \%$ of biomass/day. Samplings on weight of shrimp and milkfish well as the water quality were carned out every 15 day as, while endosulphane residue was analysed every 30 days. The results showed that thiodan applied at 2 Lha had the highest shrimp production $(29.1 \pm 5 \mathrm{~kg})$, while the thiodan applied at $1 \mathrm{~L}$ /ha had the highest milkfish production $(26.6 \mathrm{~kg})$. Analysis of endosulphane content in the flesh of shrimp and milkfish were 1,645.77 ppb and 3,879.36 ppb respectively. Residue of endosulphane showed a decreasing by an increasing of the culture period. For this fenomena, the dosage of thiodan applied at $1 \mathrm{~L} / \mathrm{h}$ a was considered safe.
\end{abstract}

KEY WORDS : endosulphane, production, residue, tiger prawn, milkfish

\section{PENDAHULUAN}

Produksi udang tambak di Indonesia mengalami peningkatan dari 15.424 ton pada tahun 1986 menjadi 98.358 ton pada tahun 1992 atau meningkat rata-rata sebesar $39,02 \%$ per tahun, kemudian menjadi 89.344 ton pada tahun 1995 atau menurun rata-rata sebesar 2,86\% per tahun dalam periode 1993-1995 (Anonim, 1997). Untuk mengantisipasi dan meningkatkan produksi melalui budi daya intensif, maka sistem pengelolaan tambak perlu dikaji dari semua aspek yang mendukung usaha budi daya, di antaranya dalam proses persiapan tambak, pemberian pakan pengontrolan kualitas air, penanganan pascapanen. pencegahan bahan polutan dan pemeliharaan kondis lingkungan yang baik serta pengendalian penyakit dan jasad pengganggu. Salah satu cara pengendalian hama dan jasad pengganggu adalah dengan menggunakan bahan kimia pestisida.

Penggunaan pestisida pada budi daya perikanan secara luas telah terbukti dapat mengendalikan

\footnotetext{
Peneliti pada Balai Penelitian Perikanan Pantai
} 
berbagai jenis hama dan jasad pengganggu, namun dapat berdampak negatif terhadap organisme budi daya seperti menurunkan sintasan, meningkatkan kandungan residu pada sedimen dan air serta kemungkinan terjadinya resurjensi dan resistensi terhadap jasad pengganggu serta mengancam keamanan pangan. Apabila keadaan ini berlangsung dalam jangka waktu lama akan berdampak pada ketidakseimbangan tatanan ekologi sehingga dapat menurunkan produksi.

Pada umumnya pestisida dan polutan lainnya yang melampaui dosis rekomendasi mempunyai pengaruh yang merugikan terhadap ekosistem dengan mengubah komposisi spesies dan jumlah populasi. Pengurangan spesies dalam ekosistem akan mengakibatkan ketidakstabilan ekosistem dan ledakan populasi spesies tertentu akibat terbunuhnya predator alami (Pimental \& Goodman, 1974).

Pestisida yang digunakan di tambak walaupun tidak terlalu persisten, pada umumnya dibuang masih dalam waktu paruhnya (Nessa, 1981). Salah satu contoh, brestan masih beracun pada hari ke-45 setelah diaplikasikan selama 7-10 hari (Djajadiredja \& Poernomo dalam Nessa, 1981). Tetapi masalah utama terhadap kesehatan masyarakat adalah adanya residu pestisida dalam bahan makanan, karena ini dapat melibatkan sejumlah orang selama jangka waktu yang panjang (Lu, 1995)

Tiodan merupakan satu di antara sekian jenis pestisida yang sering digunakan oleh petani tambak untuk mengendalikan hama dan jasad pengganggu dalam kegiatan budi daya, namun penggunaannya kadang-kadang tidak sesuai rekomendasi. Hal ini dapat memberi dampak negatif terhadap lingkungan sekitarnya dengan mengubah komposisi spesies dan jumlah populasi. Penyebaran dan konsentrasi pestisida dalam lingkungan telah dikemukakan oleh Duursma \& Hanafi (1978) dan Nessa (1981). Hasil penelitian tersebut menunjukkan bahwa residu pestisida tiodan di tambak dan sungai berkisar antara 0,00003-0,007 mg/L; di laut 0,00003--0,00042 mg/L serta di sawah 0,00015-36,00 mg/L. Juga ditemukan adanya distribusi residu pestisida dalam tubuh ikan yang banyak didapatkan pada daging, hati, dan isi perut, namun jenis dan lingkungan ikan menentukan besarnya residu.

Berdasarkan uraian di atas diduga aplikasi tiodan yang tidak terkendali akan berpengaruh terhadap kehidupan organisme di wilayah pantai dan dapat mengurangi manfaat wilayah pantai secara berkelanjutan, khususnya wilayah pertambakan sebagai lahan pemeliharaan dan penghasil udang windu sebagai komoditas andalan perikanan serta ikan bandeng yang bernilai ekonomis penting dan di- konsumsi oleh sebagian besar masyarakat Indonesia. Walaupun efek toksiknya tidak langsung segera nampak, tetapi dapat menjadi penyebab gangguan reaksi biokimia normal yang berakibat pada timbulnya berbagai penyakit kronik dan penyakit jangka panjang (Thayib, 1994).

Data dan informasi tentang pengaruh tingkat cemaran pestisida endosulfan (bahan aktif tiodan) terhadap produksi komoditas perikanan, yang merupakan salah satu kriteria kelayakan produk perikanan untuk tujuan ekspor maupun untuk konsumsi masyarakat masih terbatas. Untuk itu perlu penelitian pengaruh endosulfan terhadap produksi udang windu dan ikan bandeng di tambak serta mengetahui tingkat residu endosulfan dalam tubuhnya sebagai acuan dalam mengaplikasikan tiodan pada budi daya di tambak agar memperoleh produksi tinggi yang berkualitas baik.

\section{BAHAN DAN METODE}

Penelitian dilaksanakan dalam skala lapangan di Instalasi Tambak Percobaan Maranak, Balai Penelitian Perikanan Pantai, Maros, selama tiga bulan dari bulan Mei sampai dengan Juli 1996. Tambak yang digunakan sebanyak enam petak masing-masing dengan luas $500 \mathrm{~m}^{2} /$ petak.

Sebelum penebaran hewan uji, dilakukan persiapan tambak meliputi perbaikan pematang, pintu air, pemasangan saringan air, pengolahan tanah dasar, kedok-teplok dan pengeringan tanah dasar, kemudian dilanjutkan dengan pengapuran sebanyak $2.000 \mathrm{~kg} /$ ha. Sebagai perlakuan diaplikasikan tiodan untuk membasmi hama seperti ikan mujair, jembret (Mesopodopsis sp.) dan beberapa jenis ikan karnivora liar. Dosis tiodan yang diaplikasikan sebanyak tiga tingkatan, yaitu: $A=0,5 \mathrm{~L} / \mathrm{ha}, \mathrm{B}=1 \mathrm{~L} / \mathrm{h}$, dan $\mathrm{C}=2 \mathrm{~L} /$ ha, masing-masing perlakuan diulang dua kali. Tiodan yang digunakan dilarutkan dalam $10 \mathrm{~L}$ air, kemudian disebarkan pada bagian permukaan tambak secara merata. Selanjutnya tambak dicuci dengan menggenangi air setinggi $20 \mathrm{~cm}$ di atas pelataran dan dibuang kembali melalui pintu air yang telah dipasangi saringan.

Untuk menumbuhkan pakan alami dilakukan pemupukan dengan memakai urea dan TSP dengan perbandingan $2: 1$, kemudian air dimasukkan kembali secara bertahap sampai ketinggian $90 \mathrm{~cm}$ di atas pelataran. Setelah pakan alami tumbuh dengan normal yang ditandai perubahan warna air yang agak kehijauan, maka dilakukan penebaran benur windu (PL20) dan gelondongan bandeng secara polikultur Benur windu (Penaeus monodon) diperoleh dari unit pembenihan di Kabupaten Takalar, sedangkan gelondongan bandeng (Chanos chanos) diperoleh dari 
penggelondongan di Kabupaten Pangkep. Sebelum ditebar hewan uji diaklimatisasi selama satu minggu terhadap salinitas dan suhu sesuai kondisi tambak yang telah dipersiapkan. Penebaran benur windu sebanyak 2.000 ekordan gelondongan bandeng 150 ekor setiap petak. Pemberian pakan sebanyak 10\%/ bobot biomassa/hari dilakukan setiap pagi dan sore hari dengan jumlah yang disesuaikan dengan bobot rata-rata dari penimbangan hewan uji setiap 30 hari.

Pengamatan pertumbuhan dilakukan dengan menimbang bobot udang windu dan ikan bandeng masing-masing sebanyak 15 ekor yang diambil secara acak. Udang windu diambil dengan mengangkat anco sedangkan ikan bandeng dibius dengan menggunakan phenoxy ethano/ $200 \mathrm{mg} / \mathrm{L}$. Analisis residu endosulfan dalam tubuh kedua hewan uji dilakukan setiap 30 hari di laboratorium dengan metode Spektrofotometer Serapan Atom. Pengamatan kualitas air meliputi suhu, oksigen terlarut, salinitas, $\mathrm{pH}, \mathrm{BOT}, \mathrm{NH}_{3}, \mathrm{NO}_{2}, \mathrm{NO}_{3}$ dan $\mathrm{PO}_{4}$ dilakukan setiap 15 hari. Data yang diperoleh dianalisis secara deskriptif untuk mengetahui tingkat produksi, residu endosulfan, dan kelayakan kualitas air

\section{HASIL DAN BAHASAN}

\section{Pengaruh Tiodan terhadap Produksi Udang dan Bandeng}

Hasil penelitian menunjukkan produksi udang windu tertinggi dicapai pada aplikasi tiodan $2 \mathrm{~L} /$ ha sebesar $29,1 \pm 5 \mathrm{~kg}$ dibandingkan dengan aplikasi 0,5 dan $1 \mathrm{~L} /$ ha, sedangkan produksi ikan bandeng tertinggi diperoleh pada aplikasi tiodan $1 \mathrm{~L} / \mathrm{ha}$ sebesar $26,6 \pm 6 \mathrm{~kg}$ dibandingkan aplikasi 0,5 L/ha dan $2 \mathrm{~L} / \mathrm{ha}$ (Gambar 1).

Berdasarkan jumlah produksi yang diperoleh selama percobaan, terlihat bahwa aplikasi peningkatan dosis tiodan untuk memberantas hama dan jasad pengganggu di tambak relatif tidak berpengaruh ter- hadap peningkatan produksi bandeng. Pada aplikasi dosis 0,5 dan $1 \mathrm{~L} /$ ha terdapat peningkatan sebesar $5,1 \mathrm{~kg}(23,7 \%)$ dan dosis $2 \mathrm{~L} / \mathrm{ha}$ mengalami penurunan produksi sebesar $1,2 \mathrm{~kg}(4,5 \%)$. Sedangkan terhadap produksi udang cenderung meningkat dengan semakin tingginya dosis yang diaplikasikan, di mana produksi tertinggi pada aplikasi $2 \mathrm{~L} /$ ha dengan rataan kenaikan sebesar $5,94 \%$. Hal ini dimungkinkan oleh daya tahan organisme target terhadap bahan aktif yang diaplikasikan, sehingga ada hama yang dapat mentolerir tiodan dan sebaliknya ada yang sangat peka. Kemampuan mentolerir setiap spesies hama dan jasad pengganggu akan menentukan jumlah populasinya dalam tambak, sehingga tingkat pesaing untuk kedua hewan uji akan berbeda. Wardoyo dalam Nessa (1981) berpendapat bahwa pada umumnya ikan lebih tahan terhadap pestisida dibanding dengan zooplankton dan invertebrata air lainnya. Di antara invertebrata air, jenisjenis udang relatif lebih rentan terhadap lingkungan pestisida

Dengan demikian adanya produksi udang yang lebih tinggi pada aplikasi tiodan $2 \mathrm{~L} /$ ha dimungkinkan oleh kemampuan udang mentolerir bahan aktif endosulfan. Sebaliknya dengan semakin besarnya konsentrasi yang diaplikasikan maka toleransi hama dan jasad pengganggu udang di tambak semakin berkurang terhadap daya racun tiodan sehingga populasinya semakin berkurang bahkan dapat dibasmi. Hal ini berdampak positif terhadap udang windu yang dibudidayakan karena penyaing dalam pemberian pakan dan ruang gerak tidak ada, daya dukung tambak akan semakin baik sehingga sintasannya semakin tinggi (Tabel 1), pertumbuhan semakin cepat sehingga akan memberikan nilai produksi yang semakin tinggi. Keberadaan hama dan jasad pengganggu di tambak dapat bersifat komensalisme atau parasitisme terhadap organisme budi daya tertentu. Contoh jasad pengganggu budi daya di tambak seperti jembret (Mesopodopsis sp.), sangat

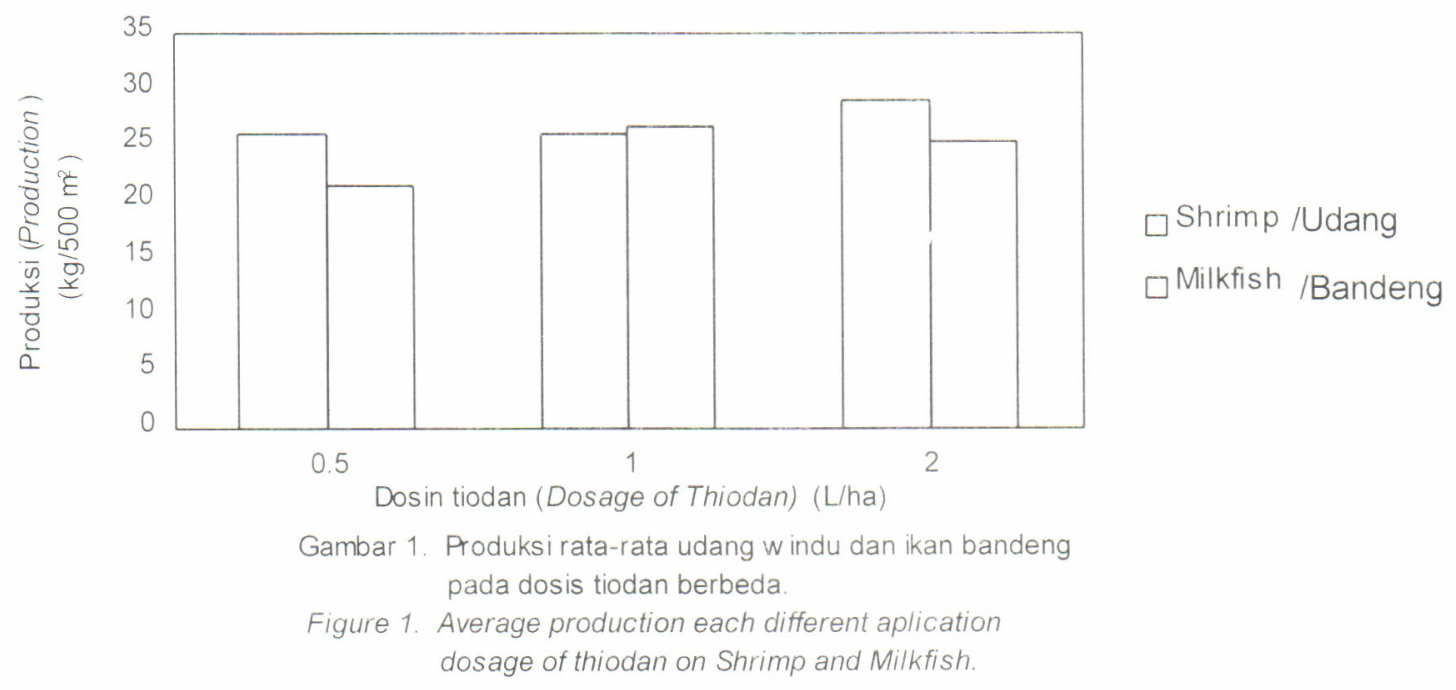


Tabel 1. Kepadatan dan sintasan udang windu dan bandeng pada aplikasi tiodan

Table 1. Density and survival rate of shrimp and milkfish at different dosage of thiodan application

\begin{tabular}{ccccc}
\hline \multirow{2}{*}{$\begin{array}{c}\text { Dosis Tiodan } \\
\text { (Dosage of Thiodan) L/ha }\end{array}$} & \multicolumn{2}{c}{ Kepadatan (Density) ind./500 $\mathbf{~ m}^{2}$} & \multicolumn{2}{c}{ Sintasan (Survival rate) \% } \\
\cline { 2 - 5 } & $\begin{array}{c}\text { Bandeng } \\
\text { Milkfish }\end{array}$ & $\begin{array}{c}\text { Udang } \\
\text { Shrimp }\end{array}$ & $\begin{array}{c}\text { Bandeng } \\
\text { Milkfish }\end{array}$ & $\begin{array}{c}\text { Udang } \\
\text { Shrimp }\end{array}$ \\
\hline 0.5 & 150 & 2000 & $91.6 \pm 6.0$ & $52.0 \pm 8.0$ \\
1 & 150 & 2000 & $93.3 \pm 6.0$ & $46.4 \pm 7.0$ \\
2 & 150 & 2000 & $87.3 \pm 7.0$ & $62.5 \pm 4.0$ \\
\hline
\end{tabular}

mengganggu dalam budi daya udang tetapi tidak berpengaruh terhadap ikan bandeng. Hasil penelitian Pong-Masak et al., (1999) mendapatkan bahwa jasad penggaggu jembret dapat dikendalikan sebesar $20,73 \%$ dengan menggunakan hostation 40 EC pada konsentrasi $0,0025 \mathrm{mg} / \mathrm{L}$ selama waktu pemaparan 24 jam.

Pengaruh dari bahan-bahan yang masuk ke dalam lingkungan perairan biasanya bervariasi antara pengaruh lama dan pengaruh sementara sebagai akibat dari berbagai faktor yang saling berinteraksi di alam dan jumlah material yang masuk, sehingga tingkatan pestisida dalam lingkungan yang memberi pengarüh nyata harus diketahui (Blackstock, 1984). Untuk itu pencapaian produksi yang tinggi perlu dikaji terhadap nilai nutrisinya serta terbebas dari unsurunsur yang menimbulkan efek negatif terhadap kesehatan manusia, sehingga dapat menjadi produk andalan.

Adanya kemerosotan kualitas wilayah pertambakan disebabkan berbagai faktor, di antaranya berbagai sumber cemaran yang masuk ke dalam lingkungan budi daya khususnya pestisida yang umumnya digunakan pada wilayah pertanian sehingga residu melalui rantai makanan akan terkumpul ke laut khususnya wilayah pesisir yang merupakan lokasi pertambakan. Matsumura (1974); Hill \& Wright (1978), dan Newman (1978) menyatakan bahwa infiltrasi pestisida pertanian ke dalam perairan tergantung pada formulasi dan aplikasi pestisida, kondisi cuaca, fisika, dan kimia tanah, serta kondisi daerah aliran sungai. Sedangkan faktor-faktor yang mempengaruhi penyebaran dan nasib pestisida di alam adalah pengenceran, degradasi secara fisika, kimia, dan biologi, penyebaran oleh materi biotik dan abiotik, transfer ke dalam rantai makanan, pembesaran secara biologi dan transfer sedimen, penguapan, fotodekomposisi, pengaruh arus, dan turbulensi, hasil metabolik ke air akibat kematian biota yang terkontaminasi atau oleh ekskresi hewan.

\section{Residu Endosulfan dalam Daging Udang dan Bandeng}

Hasil analisis residu endosulfan dalam daging udang selama pemeliharaan menunjukkan nilai yang tidak terdeteksi sampai dengan 1.645 ppb, sedangkan dalam daging bandeng tidak terdeteksi sampai dengan 2.040,37 ppb. Hasil analisis ini menunjukkan bahwa semakin tinggi dosis yang diaplikasikan, semakin besar jumlah akumulasi endosulfan dalam tubuh kedua hewan uji, namun semakin berkurang dengan makin lamanya waktu pemeliharaan (Tabel 2). Berdasarkan dosis aplikasi terlihat bahwa pada dosis terendah $(0,5 \mathrm{~L} / \mathrm{ha})$ residu endosulfan belum terdeteksi selama masa pemeliharaan, baik dalam daging udang maupun bandeng.

Adanya residu tersebut diduga sebagai akibat dari tingginya dosis tiodan yang diaplikasikan sehingga bahan aktifnya mengendap ke dasar tambak menurut tingkatan dosis dan tidak terbilas pada saat pencucian, sehingga pada awal pemeliharaan bahan aktif yang tertinggal akan terserap oleh hewan budi daya melalui oral (pencernaan), insang maupun melalui absorbsi kulit. Livingstone (1977) dalam Connel \& Miller (1995) menyatakan bahwa pengambilan pestisida oleh makhluk hidup perairan dapat disebabkan oleh pengambilan makanan yang terkontaminasi, pengambilan dari air yang melewati membran insang, difusi kutikular, dan penyerapan langsung dari sedimen. Selain itu, juga didukung oleh kebiasaan dan cara makan udang windu dan bandeng yang sering makan kelekap di dasar tambak.

Terdapat perbedaan kemampuan mengakumulasi pestisida endosulfan oleh kedua hewan uji, seperti pada aplikasi dosis $1 \mathrm{~L} /$ ha dan $2 \mathrm{~L} /$ ha masing-masing pada pemeliharaan hari ke-30 dan 60, terlihat adanya perbedaan dalam jumlah yang besar. Ikan bandeng cenderung lebih banyak mengakumulasi endosulfan dibanding udang windu. Perbedaan kemampuan mengakumulasi endosulfan oleh udang windu dan ikan 
bandeng dipengaruhi oleh berbagai faktor, baik segi biologi, fisiologi, kimiawi, maupun sifat dan mekanisme bioakumulasi dari bahan yang diaplikasikan. Selain itu terjadinya interaksi suatu bahan aktif dengan ion-ion yang ada dalam air maupun dalam tubuh makhluk hidup sehingga memungkinkan terjadinya efek sinergis dan antagonis yang dapat mempengaruhi tingkat residu bahan atau zat yang masuk dalam tubuh makhluk hidup. Nessa (1981) dalam Rachmansyah (1988) menyatakan bahwa dampak substansi terhadap organisme perairan tergantung pada jenis, komposisi dan konsentrasi substansi, jenis dan stadium organisme, kondisi lingkungan, dan lamanya pemaparan. Lebih lanjut dinyatakan bahwa pada umumnya ikan lebih tahan terhadap pestisida dibanding dengan plankton hewani dan invertebrata air. Dari hasil penelitian Rachmansyah et al. (1997) diketahui bahwa ikan bandeng dengan ukuran kecil cenderung mengakumulasi endosulfan lebih banyak dibandingkan ukuran besar, demikian juga pada salinitas rendah (20 ppt) memiliki potensi residu lebih besar dibandingkan salinitas tinggi (30 ppt). Lebih lanjut Lu (1995) berpendapat bahwa faktor-faktor yang mempengaruhi pengambilan dan penyebaran pestisida dalam sistem biologi dikaitkan dengan (1) sifat fisik dan kimiawi inheren dan pestisida (misalnya volatilitas, kelarutan dalam air, dan lemak, serta karakteristik absorpsi); (2) karakteristik fisiologi berbagai spesies (misalnya perilaku makan, jalur pengambilan, dan habitat; serta (3) sifat spesifik ekosiseim (misalnya jenis sistem aliran, suhu, $\mathrm{pH}$, bahan organik, dan struktur jaring makanan.

Pestisida mempunyai berbagai sumber di tambak dan dapat berpengaruh akut maupun kronis terhadap biota budi daya. Pengaruh kronis dapat terjadi dengan merusak fungsi fisiologi atau perilaku, tetapi tidak menyebabkan kematian langsung meskipun kematian dapat terjadi karena gangguan terhadap proses makan, pertumbuhan atau perilaku yang tidak normal, lebih mudah tertangkap pemangsa, kurangnya kemampuan berkelompok, atau sebab-sebab lain yang tidak langsung. Pengaruh ini tidak hanya menyebabkan perubahan dalam populasi individu, tetapi juga menyebabkan pergeseran komposisi serta diversifikasi spesies. Hasil penelitian distribusi endosulfan di perairan pantai barat Sulawesi Selatan menunjukkan bahwa residu endosulfan telah terdeteksi di sebagian besar contoh yang diambil. Sebanyak 27 contoh $(40,9 \%)$ dari total contoh 66 , telah terdeteksi mengandung residu endosulfan dengan kisaran 22,7133.962,04 ppb (Rachmansyah et al., 1999). Karena itu, aplikasi tiodan di perairan tambak memiliki potensi residu yang lebih besar.

Laju akumulasi endosulfan oleh udang windu dan bandeng serta lama retensi dalam tubuhnya menjadi sangat penting bagi keamanan konsumer maupun untuk aplikasi endosulfan pada kegiatan budi daya. Hasil percobaan menunjukkan bahwa residu endosulfan dalam tubuh udang windu tidak terdeteksi setelah 60 hari pemeliharaan pada aplikasi satu L/ha dan 90 hari pada ikan bandeng dengan aplikasi. Dengan demikian, apabila mengaplikasikan konsentrasi tersebut, maka panen setelah umur 60 hari dan 90 hari masing-masing untuk udang windu dan ikan bandeng dianggap aman untuk dikonsumsi. Lu (1995) berpendapat bahwa untuk melindungi kesehatan konsumen, ditentukan suatu standar legal dalam bentuk "toleransi" (juga dikenal sebagai "batas residu maksimum"). Standar itu memberikan tingkat maksimum yang direkomendasikan dalam tiap komoditas makanan yang mungkin meninggalkan residu pestisida akibat penggunaannya dalam tahap sebelum penanaman, pertumbuhan, pemanenan, dan penyimpanan hasil panen. Kandungan residu pestisida dalam produk hasil laut yang aman bagi konsumen tidak boleh lebih dari 20 ppb (SK MENEG KLH No.Kep-02/MENKL.H/l/1988).

Tabel 2. Residu endosulfan ( $\quad$ ppb) dalam daging udang windu (Penaeus monodon) dan ikan bandeng (Chanos chanos) pada aplikasi dosis tiodan berbeda.

Table 2. Residue of endosulfan ( $p p b)$ as the effect of the different thiodan dosages application on the flesh on shrimp (Penaeus monodon) and milkfish (Chanos chanos)

\begin{tabular}{|c|c|c|c|c|c|c|}
\hline \multirow{3}{*}{$\begin{array}{c}\text { Dosis Thiodan } \\
\text { (Dosage of Thiodan) L/ha }\end{array}$} & \multicolumn{6}{|c|}{ Residu endosulfan dalam daging (Residu of endosulfan (ppb) in flesh) } \\
\hline & \multicolumn{3}{|c|}{ Udang hari ke-(Shrimp at day) } & \multicolumn{3}{|c|}{ Bandeng hari ke-(Milkfish at day) } \\
\hline & 30 & 60 & 90 & 30 & 60 & 90 \\
\hline 0.5 & Ud & Ud & Ud & Ud & Ud & Ud \\
\hline 1 & 849.01 & Ud & Ud & $2,040.37$ & $1,493.94$ & Ud \\
\hline 2 & 1.645 .00 & 384.18 & 81.97 & $3,879.36$ & $2,543.74$ & Ud \\
\hline
\end{tabular}

Note: $U d=$ undetected 
Tabel 3. Rata-rata nilai kualitas air pada setiap petak perlakuan dan saluran air selama penelitian

Table 3. Average values of water quality parameters at each treated ponds and pond canal during the experiment

\begin{tabular}{|c|c|c|c|c|}
\hline \multirow{2}{*}{$\begin{array}{l}\text { Parameter kualitas air } \\
\text { Parameter of water quality }\end{array}$} & \multicolumn{3}{|c|}{ Perlakuan (Treatment) } & \multirow{2}{*}{$\begin{array}{l}\text { Saluran tambak } \\
\text { Pond canal }\end{array}$} \\
\hline & $\bar{A}$ & B & $\bar{C}$ & \\
\hline Temp. (OC) & $25.0 \pm 0.3$ & $28.4 \pm 2.0$ & $28.7 \pm 1.8$ & $27.5 \pm 4.0$ \\
\hline $\mathrm{DO}(\mathrm{pp})$ & $4.8 \pm 1.2$ & $4.3 \pm 1.3$ & $4.8 \pm 1.6$ & $3.6 \pm 1.7$ \\
\hline $\mathrm{pH}$ & $8.3 \pm 0.4$ & $8.2 \pm 0.5$ & $8.4 \pm 0.4$ & $7.7 \pm 0.2$ \\
\hline Salinity (ppt) & $21.4 \pm 11.4$ & $21.9 \pm 11.3$ & $22.8 \pm 11.9$ & $17.3 \pm 12.6$ \\
\hline BOT (mg/L) & $8.85 \pm 1.79$ & $6.95 \pm 2.68$ & $12.0 \pm 1.6$ & $2.52 \pm 0.0$ \\
\hline TSS (mg/L) & $306,0 \pm 180.4$ & $269.4 \pm 131.7$ & $338.5 \pm 259.5$ & $53 \pm 0.0$ \\
\hline $\mathrm{NH}_{3}(\mathrm{mg} / \mathrm{L})$ & $0.0476 \pm 0.0286$ & $0.0468 \pm 0.0290$ & $0.0521 \pm 0.0293$ & $0.0557 \pm 0.0317$ \\
\hline $\mathrm{NO}_{2}(\mathrm{mg} / \mathrm{L})$ & $0.0133 \pm 0.0095$ & $0.0139 \pm 0.0122$ & $0.0118 \pm 0.0125$ & $0.0933 \pm 0.1312$ \\
\hline $\mathrm{NO}_{3}(\mathrm{mg} / \mathrm{L})$ & $0.0043 \pm 0.0001$ & $0.0043 \pm 0.0001$ & $0.0045 \pm 0.0002$ & $0.0055 \pm 0.0020$ \\
\hline $\mathrm{PO}_{4}(\mathrm{mg} / \mathrm{L})$ & $0.1029 \pm 0.0525$ & $0.1122 \pm 0.0374$ & $0.1175 \pm 0.0513$ & $0.1895 \pm 0.0131$ \\
\hline
\end{tabular}

Catatan (Note) : $A=0.5 \mathrm{~L} / \mathrm{ha}$ of thiodan; $\mathrm{B}=1 \mathrm{~L} / \mathrm{ha}$ of thiodan; $\mathrm{C}=2 \mathrm{~L} / \mathrm{ha}$ of thiodan

\section{Kualitas Air}

Hasil pemantauan kualitas air selama percobaan memperlihatkan kisaran kelayakan bagi budi daya udang dan ikan bandeng (Tabel 3.). Nilai kisaran beberapa parameter sebagai berikut : suhu air antara $25-28,7^{\circ} \mathrm{C}$; oksigen terlarut $4,3-4,8 \mathrm{mg} / \mathrm{L} ; \mathrm{pH} 8,2-$ 8,4 ; salinitas $21,4-22,8 \mathrm{ppt}$; BOT $6,95-12,0 \mathrm{mg} / \mathrm{L}$; $\mathrm{NH}_{3} 0,0468-0,0521 \mathrm{mg} / \mathrm{L} ; \mathrm{NO}_{2} 0,0118-0,0139 \mathrm{mg} / \mathrm{L}$; $\mathrm{NO}_{3} 0,0043-0,0045 \mathrm{mg} / \mathrm{L} ;$ dan $\mathrm{PO}_{4}-1029-0,1175 \mathrm{mg} /$
L. Kisaran-kisaran tersebut memenuhi persyaratan kelayakan bagi organisme yang dibudidayakan jika dibandingkan kutipan beberapa kisaran dari beberapa sumber (Tabel 4.).

Kualitas air di tambak secara umum dapat diartikan sebagai kondisi air yang memungkinkan udang dapat hidup dan tumbuh lebih baik (Boyd, 1983). Agar udang dapat hidup dan tumbuh dengan baik, kualitas air harus berada dalam persyaratan sifat fisik kimiawinya. Jaya et al. (1994) menyatakan bahwa

Tabel 4. Kisaran nilai kualitas air yang layak untuk budi daya udang dan ikan bandeng

Table 4. Ranges of suitable and optimum values of the water quality parameter for shrimp and milkfish culture.

\begin{tabular}{lcc}
\hline $\begin{array}{c}\text { Parameter kualitas air } \\
\text { Parameter of water quality }\end{array}$ & $\begin{array}{c}\text { Kisaran layak } \\
\text { Suitable ranges }\end{array}$ & $\begin{array}{c}\text { Nilai optimum } \\
\text { Optimum value }\end{array}$ \\
\hline Temperature $\left({ }^{\circ} \mathrm{C}\right)$ & $26-32$ & $29-30$ \\
$\mathrm{DO}(\mathrm{mg} / \mathrm{L})$ & $3-10$ & $4-7$ \\
$\mathrm{pH}$ & $7.5-8.7$ & $7.5-8.3^{*}$ \\
& & Fluktuasi harian \\
(Daily fluctuation)
\end{tabular}


tingkat keberhasilan usaha budi daya organisme perairan sangat ditentukan oleh kondisi tempat hidupnya. Kondisi lingkungan dimaksud adalah kualitas air tambak dan tanah sedimen. Kondisi lingkungan perairan relatif tidak stabil ketimbang kondisi terestrial. Dinamika kondisinya mudah terpengaruh oleh bahan yang terlarut, iklim mikro, dan perlakuan manusia.

\section{KESIMPULAN DAN SARAN}

\section{Kesimpulan}

Berdasarkan analisis pengaruh aplikasi endosulfan terhadap produksi udang windu (Penaeus monodon) dan ikan bandeng (Chanos chanos) di tambak, maka dapat disimpulkan sebagai berikut

1. Aplikasi tiodan $2 \mathrm{~L} / \mathrm{ha}$ tambak memberi produksi udang windu tertinggi $(29,1 \pm 5 \mathrm{~kg})$ dan $1 \mathrm{~L} / \mathrm{ha}$ terhadap bandeng $(26,6 \pm 6 \mathrm{~kg})$.

2. Ikan bandeng lebih berpotensi mengakumulasi endosulfan dibandingkan udang windu, di mana residu tidak terdeteksi dalam daging udang windu pada aplikasi $1 \mathrm{~L} / \mathrm{ha}$ sedangkan dalam ikan bandeng tidak terdeteksi pada aplikasi 2 L/ha

3. Pada budi daya polikultur udang windu dan bandeng, maka endosulfan dapat diaplikasikan 1 L/ha.

\section{Saran}

Penanggulangan hama dan jasad pengganggu di tambak dengan menggunakan tiodan disarankan untuk tidak diaplikasikan mengingat potensi residu endosulfan cukup besar baik di sedimen, kelekap, dan organisme budi daya

\section{DAFTAR PUSTAKA}

Anonim, 1997. Statistik Perikanan Indonesia 1995 Direktorat Jenderal Perikanan, Departemen Pertanian, Jakarta. $74 \mathrm{pp}$.

Boyd, E.C., 1983. Theory of aeration. In Water Quality In Channel Catfish Ponds. Southern Coorporation Series Bulletin (290) : 13-32.

Chanratchakool, P., Turnbull, F.J., Funge-Smith, J.S., MacRae,H.I., and Limsuwan, C., 1998. Health Management in Shrimp Ponds. Third Edition. Aquatic Animal Health Research Institute, Department of Fisheries, Kasetsart University Campus, Bangkok. $152 \mathrm{pp}$.

Connell, D.W. and Miller, G.J., 1995. Kimia dan Ekotoksikologi Pencemaran. (Penerjemah : Yanti Koestoer), Universitas Indonesia. Jakarta. 520 pp.

Duursma, E.K. and A. Hanafi, 1978. Use of pesticides in brackishwater pond:3. Distribution of Chlorinate
Pesticides in Enveriomental Samples. Bull. Shrimp Cult. Res. Cent, II (1+2) : 114-142.

Hill, I.R and S.J.L. Wright. 1978. The behaviour fate of pesticides in mikrobial environments. In Hill I.R. \& S.J.L. Wright (Eds.) Pesticide Microbiology : Microbial Aspects of Pesticide Behaviour in the Environment. Academic Press, London. p: 79-136

Jaya, S.I., Utaminingsih dan Hermiyaningsih, 1994. Pedoman Analisis Kualitas Air dan Tanah Sedimen Perairan Payau. Ditjen Perikanan, Balai Budi Daya Air Payau, Jepara. 43 pp

Lu, C.F., 1995. Toksikologi Dasar, Asas, Organ Sasaran dan Penilaian Resiko. Edisi kedua, Penerjemah Edi Nugroho. Universitas Indonesia Press, Jakarta. 282 pp.

Matsumura, F. 1974. Mikrobial degradation of pesticides, In M.A.Q. Khan and J.P. Berdeka (Eds), Survival in Toxic Environment. Academic Press, Inc., New York, San Fransisco, London. p: 129-154

Nessa, M.N., 1981. Pengaruh Sampingan Penggunaan Pestisida dan Pupuk di Tambak terhadap Organisme Estuaria. Fakultas Pascasarjana IPB, Bogor. 213pp

Newman J.F. 1978. Pesticides, In Hill,I.R. \& S.J.L. Wright (Eds.). Pesticides Microbiology: Microbiology Aspects of Pesticides Behaviour in the Environment. Academic Press, London. p:1-17

Pimental D. and Goodman, 1974. Environment impact of pesticides, In Khan, M.A.Q. \& J.P. Berdeka (Eds.) Survival in Toxic Environments. Academic Press, Inc. New York, San Fransisco, London. p : 25-52

Pong-Masak, P.R. dan Rachmansyah, 1999. Uji toksisitas Hostathion 40 EC terhadap mortalitas jembret (Mesopodopsis sp.) dan sintasan pascalarva udang windu (Penaeus monodon). Jurnal Fakultas Perikanan Universitas Sam Ratulangi, Manado, Vol. I (1). p.39-46

Poernomo, A., 1988. Faktor lingkungan yang dominan pada budi daya udang intensif. Seminar Usaha Budi Daya Tambak, Surabaya. 63 pp.

Rachmansyah, P. R. Pong-Masak, N. Hattu, dan M Rahmat, 1997. Analisis residu pestisida tiodan 35 EC dalam tubuh ikan bandeng (Chanos chanos Forskal) pada tingkat ukuran dan salinitas berbeda Laporan Hasil Penelitian, Balai Penelitian Perikanan Pantai, Maros. 16pp

Rachmansyah, 1988. Dampak Penggunaan Pestisida terhadap Jumlah dan Keragaman Kelekap serta Produksi Biomassa Benur Windu. (tesis) Fakultas Pascasarjana Universitas Hasanuddin, Ujung Pandang. $104 \mathrm{pp}$

Rachmansyah, Usman, Reni Yulianingsih, and I.N Radiarta, 1999. Distribusi residu endosulfan di perairan pantai barat Sulawesi Selatan. Jurnal Penelitian Perikanan Indonesia, Vol.V(2):68-82.

Thayib, H.M., 1994. Pencemaran Ekosistim Laut dan Tata Ruang, dalam Prosiding Seminar Pemantauan Pencemaran Laut, Jakarta. p:130-141 